\title{
Comparison of a coupled snow thermodynamic and radiative transfer model with in situ active microwave signatures of snow-covered smooth first-year sea ice
}

\author{
M. C. Fuller, T. Geldsetzer, J. Yackel, and J. P. S. Gill \\ Cryosphere Climate Research Group, University of Calgary, Calgary, Canada \\ Correspondence to: M. C. Fuller (mcfuller@ucalgary.ca) \\ Received: 6 April 2015 - Published in The Cryosphere Discuss.: 24 June 2015 \\ Revised: 30 September 2015 - Accepted: 29 October 2015 - Published: 18 November 2015
}

\begin{abstract}
Within the context of developing data inversion and assimilation techniques for C-band backscatter over sea ice, snow physical models may be used to drive backscatter models for comparison and optimization with satellite observations. Such modeling has the potential to enhance understanding of snow on sea-ice properties required for unambiguous interpretation of active microwave imagery. An end-to-end modeling suite is introduced, incorporating regional reanalysis data (NARR), a snow model (SNTHERM89.rev4), and a multilayer snow and ice active microwave backscatter model (MSIB). This modeling suite is assessed against measured snow on sea-ice geophysical properties and against measured active microwave backscatter. NARR data were input to the SNTHERM snow thermodynamic model in order to drive the MSIB model for comparison to detailed geophysical measurements and surface-based observations of C-band backscatter of snow on first-year sea ice. The NARR variables were correlated to available in situ measurements with the exception of long-wave incoming radiation and relative humidity, which impacted SNTHERM simulations of snow temperature. SNTHERM snow grain size and density were comparable to observations. The first assessment of the forward assimilation technique developed in this work required the application of in situ salinity profiles to one SNTHERM snow profile, which resulted in simulated backscatter close to that driven by in situ snow properties. In other test cases, the simulated backscatter remained 4$6 \mathrm{~dB}$ below observed for higher incidence angles and when compared to an average simulated backscatter of in situ endmember snow covers. Development of C-band inversion and assimilation schemes employing SNTHERM89.rev4 should consider sensitivity of the model to bias in incoming long-
\end{abstract}

wave radiation, the effects of brine, and the inability of SNTHERM89.Rev4 to simulate water accumulation and refreezing at the bottom and mid-layers of the snowpack. These impact thermodynamic response, brine wicking and volume processes, snow dielectrics, and thus microwave backscatter from snow on first-year sea ice.

\section{Introduction}

Snow cover plays an important role in radiative transfer interactions due to its thermal capacity, conductivity, diffusivity, and albedo (Robok, 1983). Snow cover curtails the heat and energy exchange across the ocean-sea-ice-atmosphere interface and, therefore, exerts control over sea-ice formation, ablation, extent, and thickness processes (Maykut, 1982; Curry et al., 1995; Sturm et al., 2009). This is important to the global climate system due to the significant amount of energy involved in sensible and latent heat fluxes (Serreze and Barry, 2005) and the influence of snow due to its relatively high albedo. Snow albedo is influenced by grain size, which both is affected by and effects radiant exchanges. The distribution and geophysical character of snow cover over sea ice are highly variable both spatially and temporally and will undergo distinct melt and freeze cycles when forced by the same atmospheric event, based on the geophysical character and layered arrangement of snow mass (snow water equivalent, SWE). This difference in thermal response affects the basal snow layer brine volume and snow grain development, which may be used to discriminate snow thickness and water equivalent through use of remotely sensed 
microwave backscatter (Barber and Nghiem, 1999; Yackel and Barber, 2007; Langlois et al., 2007). Snow cover on sea ice is typically represented in physical and backscatter models as a two- or three-layer system of fine grained fresh snow or dense wind slab, overlying more coarsely grained depth hoar of lower density, and brine-covered basal snow (e.g., Crocker, 1992; Barber et al., 1995; Geldsetzer et al., 2007). However, increases in the alternation of early spring rain, snow, and melt events (Trenberth et al., 2007) can result in a more complex layering of snow. This increase in the number of ice lenses, drainage channels, and inclusions affects the thermodynamic response of various configurations of snow cover to subsequent forcing. This in turn affects snow grain development, drainage, brine distribution, and seasonal melt processes (Colbeck, 1991) pertinent to C-band microwave backscatter over first-year sea ice (Fuller et al., 2014). Improvements in geophysical inversion from microwave imagery may in turn be used to improve snow modeling (Pulliainen, 2006; Durand, 2007; Geldsetzer et al., 2007).

Changes to the composition of sea ice in the Arctic system affect the accuracy of geophysical and thermodynamic properties, which are required for management strategies (Barber, 2005; Warner et al., 2013). An expected increase in the rate of both early and late season precipitation and melt events in the Arctic will add complexity to both snow thermodynamic modeling and interpretation of microwave remote sensing data, as multiple snow and ice conditions can lead to similar backscatter results (Barber et al., 2009; Warner et al., 2013; Gill and Yackel, 2012; Gill et al., 2014; Fuller et al., 2014). In such cases, a snow thermodynamic model may be used for comparison and inversion of important snow properties (e.g., snow water equivalent (SWE), grain size) for a given backscatter response. Satellite-based remote sensing provides a larger scale of observation; however, errors stem from relating backscatter values to snow and ice structure and dielectrics (Durand, 2007). Potential solutions to these issues are being developed in state-of-the-art data assimilation techniques, which may solve issues of spatial and temporal coverage, observability, and spatial and temporal resolution (Reichle, 2008). These systems update snow physical and radiative models with available in situ snow and meteorological observations (Sun et al., 2004; Andreadis and Lettenmaier, 2006; Pulliainen, 2006; Durand, 2007). These are focused toward providing estimates for large areas with few in situ observations, such as the Canadian Arctic (Matcalfe and Goodison, 1993; Langlois et al., 2009). Accurate representations of snow density, albedo, and storage and refreezing of liquid water in the snowpack, as inputs to snow models, are required for consistent results (Essery et al., 2013). Inversion or assimilation schemes that focus on C-band backscatter in the Canadian Arctic may encounter error, as in situ conditions may not be as they appear in ice charts and satellite imagery (e.g., Barber et al., 2009; Warner et al., 2013).

The Canadian Ice Service (CIS) integrates, analyses, and interprets many data sources to produce weekly regional charts estimating properties such as ice type, thickness, and concentration; however, these may contain inaccuracies (e.g., Barber et al., 2009; Warner et al., 2013). The simulation of snow physical properties relevant to backscatter can lend insight to the actual cause of the microwave response, and is necessary given the vast scale of the Canadian Arctic, which has relatively few in situ climate or snow physical observations.

This work represents the first assessment of the suitability of an operational end-to-end weather-snow-backscatter estimation technique over first-year sea ice. It employs reanalysis data, a one-dimensional snow evolution model, and an active microwave backscatter model. The models and simulated outputs are North American Regional Reanalysis (NARR), the snow thermodynamic model (SNTHERM) of Jordan (1991), and a multilayer snow and ice backscatter model (MSIB); each of these are described in Sects. 2.3 and 2.4. These model analyses are necessary in part to evaluate the error in ice charts and satellite observations, particularly when considering the effects of more complexly layered snow (e.g., Fuller et al., 2014). Previous work has considered the use of NARR variables to compare snow models over land (e.g., Langlois et al., 2009) and the simulation of passive microwave emission (MEMLS) from physical snow models (SNOWPACK) driven by NARR data over land (e.g., Wiesmann et al., 2000; Langlois et al., 2012). NARR variables were used to drive SNTHERM and subsequently the HUT emission model for soil temperature estimation (e.g., Kohn and Royer, 2010) and for downwelling microwave emission estimation over land (e.g., Roy et al., 2012; Montpetit et al., 2013). A recent study by Proksch et al. (2015) compared MEMLS-simulated backscatter to SnowScat observations with reasonable agreement. Willmes et al. (2014) employed European Re-Analysis data to drive SNTHERM and subsequently MEMLS for simulation of passive microwave emission of snow and sea ice. To the authors' knowledge, this study represents the first assessment of an end-to-end modeling suite to estimate active microwave backscatter over sea ice. The use of NARR data to drive a snow thermodynamic model, which in turn drives an active microwave backscatter model at C-band, provides a novel methodology to resolve snow and ice properties that produce ambiguity in active microwave image interpretation.

\section{Objectives}

The overall focus of this work lies in the operational application of SNTHERM derived snow properties to MSIB simulated backscatter. As such, NARR meteorological data are used to drive the SNTHERM snow model for comparison with case studies of observed snow properties and with plotscale modeled and observed backscatter for layered snow on first-year sea ice. The overarching research question we address is whether NARR-driven SNTHERM simulated snowpack layers, used in the MSIB backscatter model, can re- 
produce observed backscatter for snow-covered first-year sea ice.

The specific questions addressed are as follows.

1. How does NARR compare to in situ meteorological data with regard to variables of importance to SNTHERM89.rev4?

2. How does SNTHERM89.rev4 output compare to in situ snow structure and geophysical properties relevant to $\mathrm{C}$ band microwave backscatter over first-year sea ice?

3. How do simulated backscatter signatures based on SNTHERM89.rev4 output compare to simulations from observed snow structure and properties and observed backscatter for complexly layered snow over first-year sea ice?

4. What are the implications of the use of the SNTHERM89.rev4 thermodynamic model in an operational approach for a radiative transfer simulation of C-band backscatter over first-year sea ice?

\section{Methods}

\subsection{Study area}

The study area is located near Churchill, Manitoba, and took place in 2009 from 7 April through 15 May on landfast firstyear sea ice in Bird Cove $\left(58.812^{\circ} \mathrm{N}, 093.895^{\circ} \mathrm{W}\right)$, Hudson Bay. This site is fully described in Fuller et al. (2014). Samples were acquired on a smooth $4 \mathrm{~km}$ by $1.5 \mathrm{~km}$ pan of first-year sea ice and included detailed snow geophysical and surface-based C-band backscatter measurements.

\subsection{Data collection}

\subsubsection{Meteorological data}

The in situ meteorological instruments were located on sea ice $500 \mathrm{~m}$ adjacent to the snow sample sites and measured relative humidity $(\mathrm{RH})$, sampled every $10 \mathrm{~min}$ and averaged to hourly data. Environment Canada's "Churchill A" station $\left(58.733^{\circ} \mathrm{N}, 094.050^{\circ} \mathrm{W}\right)$ is on land approximately $20 \mathrm{~km}$ from the study site and measured air temperature. The NOAA NCEP NARR data were downloaded for the $32 \mathrm{~km}$ grid containing the sample site. These data included reanalysis of air temperature, $\mathrm{RH}$, wind speed, long-wave and shortwave incoming and outgoing radiation, and precipitation amount. The NARR grid data were resampled from $3 \mathrm{~h}$ to hourly data using a linear interpolation and contain a roughly even split of land and bay. Operationally, in order to match the location of snow geophysical sampling, the observed backscatter, and the state variables required to drive SNTHERM, we employed a NARR grid spanning sea ice and snow-covered land. The effects of the grid encompassing the transition zone may be a source of error.

\subsubsection{Snow geophysical data}

Snow geophysical data were collected directly adjacent to the surface-based scatterometer. Measurements of temperature, density, snow microstructure, dielectrics, and salinity were acquired every $2 \mathrm{~cm}$ in vertical profile. The snow grain major and minor axis and morphology were determined visually from samples placed and photographed on a standard grid card. The snow samples are referred to as samples 13 , and were selected to represent the observed variation of snow geophysical character. These provide a basis for a comparison of observed and simulated backscatter for a modeled snow and sea-ice layering analysis, which is conducted in Fuller et al. (2014). The geophysical properties of samples 1, 2 , and 3 are compared to those provided by SNTHERM when forced by NARR data (Sect. 3.2 and its associated figures).

\subsubsection{Scatterometer data}

The surface-based C-band backscatter measurements $\left(\sigma_{\mathrm{VV}}^{0}\right.$, $\left.\sigma_{\mathrm{HH}}^{0}\right)$ were acquired continuously throughout the day (15 May 2009) for a $20-70^{\circ}$ elevation range (in $2^{\circ}$ increments) and an $80^{\circ}$ azimuthal range (where the first and second letters indicate the emitted and received polarizations, respectively). The scatterometer was fixed in location and was mounted at a height of $2.2 \mathrm{~m}$. The system specifications are in Table 1. The validation of the system is described in Geldsetzer et al. (2007) and measurement techniques pertinent to this study are described further in Fuller et al. (2014).

\subsection{SNTHERM and NARR}

SNTHERM is a one-dimensional, multilayer thermodynamic model originally developed for snow temperature simulations (Jordan, 1991) and later adapted for sea ice (Jordan and Andreas, 1999). SNTHERM uses hourly meteorological variables to simulate thermodynamic processes of air, soil, and liquid, solid, and vapor states of water. The simulated outputs include snow cover properties such as temperature, SWE, grain size, liquid water content, layer thickness, and depth, which are relevant to microwave remote sensing. The model predicts grain growth from thermal and vapor gradients and albedo and accounts for water percolation, which is artificially drained from the bottom of the snowpack-surface interface. It requires an initial state of snow and ice character including, the number of layers (nodes), grain size, density, temperature, mineral density, heat capacity, and thermal conductivity. Heat fluxes are transferred from snow to ice, which in turn updates snow temperatures at each time step. Operational concerns, and sparsely detailed in situ meteorological data for large areas of the Canadian Arctic, can require the use of reanalysis data. NARR data are high resolution ( $32 \mathrm{~km}$ grid) and computed in near-real time in $3 \mathrm{~h}$ time steps (Mesinger et al., 2006). It provides detailed temperature, wind speed, relative humidity, radiation, and precipita- 
Table 1. C-band scatterometer specifications.

\begin{tabular}{ll}
\hline RF output frequency & $5.5 \mathrm{GHz} \pm 2.50 \mathrm{MHz}$ \\
Antenna type & $0.61-\mathrm{m}$ parabolic reflector, dual linear polarization \\
Antenna beamwidth & $5.4^{\circ}$ \\
Cross polarization isolation & $>30 \mathrm{~dB}$, measured at the peak of the beam \\
Transmit power & $12 \mathrm{dBm}$ \\
Bandwidth & $5-500 \mathrm{MHz}$, user adjustable \\
Range resolution & $0.30 \mathrm{~m}$ \\
Polarization mode & Polarimetric $(\mathrm{HH}, \mathrm{VV}, \mathrm{HV}, \mathrm{VH})$ \\
Noise floor & $\mathrm{Co} \sim-36 \mathrm{dBm}$, cross $\sim-42 \mathrm{dBm}$ \\
External calibration & Trihedral corner reflector \\
\hline
\end{tabular}

tion data necessary to SNTHERM. NARR has shown good correlation with ground-based meteorological measurements and plot-scale in situ observations for snow and soil thermodynamic and passive microwave radiometric modeling (e.g., Langlois et al., 2009; Kohn and Royer, 2010).

The latest publicly available SNTHERM89.rev4 was used in this work and as such does not treat sea ice specifically; however, sea-ice parameters can be entered as layers in the model to account for its thermal capacity and conductivity. SNTHERM uses hourly meteorological variables including air temperature $(\mathrm{K})$, relative humidity $(\%)$, wind speed $\left(\mathrm{m} \mathrm{s}^{-1}\right)$, incoming and outgoing shortwave radiation and incoming long-wave radiation $\left(\mathrm{W} \mathrm{m}^{-2}\right)$, precipitation amount (SWE, $\mathrm{mm}$ ), and effective precipitation particle size (m). For each precipitation event, SNTHERM adds a new layer to the top of the snowpack; the layer is combined with the one below if and when the layer thickness reaches a prescribed minimum (Jordan, 1991; Durand, 2007). SNTHERM bases grain growth for dry snow on current grain size and vapor flux through the snowpack, with a set maximum flux and kinetic growth limit of $5 \mathrm{~mm}$ grain diameter. The model assumes no vapor flux between the snow and bottom surface layer (Jordan, 1991; Jordan and Andreas, 1999), resulting in slowing grain growth for the layer directly above (Durand, 2007). Relevant to MSIB, SNTHERM output provides layer thickness (m), density $\left(\mathrm{kg} \mathrm{m}^{-3}\right)$, snow or ice layer temperature $(\mathrm{K})$, and average layer grain size diameter (m) (Jordan, 1991; Langlois et al., 2009). NARR meteorological data were used to drive SNTHERM in all cases. The outgoing shortwave radiation was recalculated to $85 \%$ of the incoming shortwave radiation as per Curry et al. (1995) (explored in Sect. 3.1). SNTHERM was run under two different geophysical initial conditions to test sensitivity to initial condition inputs, as the model run was for 38 continuous days from 7 April to 15 May (Table 2):

- SNTHERM A: $2 \mathrm{~cm}$ fresh ice superimposed over firstyear sea ice, representative of bare ice conditions observed on 7 April, before a snow event.

- SNTHERM B: $10 \mathrm{~cm}$ of snow over a $2 \mathrm{~cm}$ fresh ice layer, superimposed over first-year sea ice, representa-
Table 2. Initial conditions for cases A and B. Note small artificial grain sizes input for sea ice. These values were also tested at $0.001 \mathrm{~m}$ and did not affect the results of the simulations.

\begin{tabular}{lrrr}
\hline Layer & $\begin{array}{r}\text { Thickness } \\
(\mathrm{m})\end{array}$ & $\begin{array}{r}\text { Density } \\
\left(\mathrm{kg} \mathrm{m}^{-3}\right)\end{array}$ & $\begin{array}{r}\text { Grain } \\
\text { diameter }(\mathrm{m})\end{array}$ \\
\hline \multicolumn{4}{l}{ SNTHERM } \\
\hline Fresh ice & 0.02 & 915 & 0.001 \\
Sea ice & 1.52 & 915 & 0.0001 \\
\hline \multicolumn{4}{l}{ SNTHERM } \\
\hline Snow & 0.02 & 202.8 & 0.001 \\
Snow & 0.02 & 221.5 & 0.001 \\
Snow & 0.02 & 221 & 0.001 \\
Snow & 0.02 & 210 & 0.001 \\
Snow & 0.02 & 248.7 & 0.001 \\
Fresh ice & 0.02 & 915 & 0.001 \\
Sea ice & 1.52 & 915 & 0.0001 \\
\hline
\end{tabular}

tive of in situ observations taken 8 April, after a snow event.

The hourly meteorological state variables used include $2 \mathrm{~m}$ air temperature, $2 \mathrm{~m}$ relative humidity, $10 \mathrm{~m}$ wind speed, incoming and outgoing shortwave radiation and incoming long-wave radiation, and precipitation amount. Initial condition input variables include the number of layers, layer thickness, associated density, associated grain size, average barometric pressure $(1018 \mathrm{mb}$, averaged from Churchill A measurements concomitant to the 38 day SNTHERM run), snow albedo (0.85), and new snow density $\left(100 \mathrm{~kg} \mathrm{~m}^{-3}\right)$. The sea-ice initial state variables are proportion of brine $(6 \%)$, bulk density $\left(915 \mathrm{~kg} \mathrm{~m}^{-3}\right)$ (Carsey, 1992) heat capacity (2100 $\left.\mathrm{J} \mathrm{kg} \mathrm{K}^{-1}\right)$, and emissivity (0.86) (Wadhams, 2000), and thermal conductivity $\left(1.96 \mathrm{~W} \mathrm{~m} \mathrm{~K}^{-1}\right.$ ) (Schwerdtfeger, 1963; Trodahl et al., 2001). 


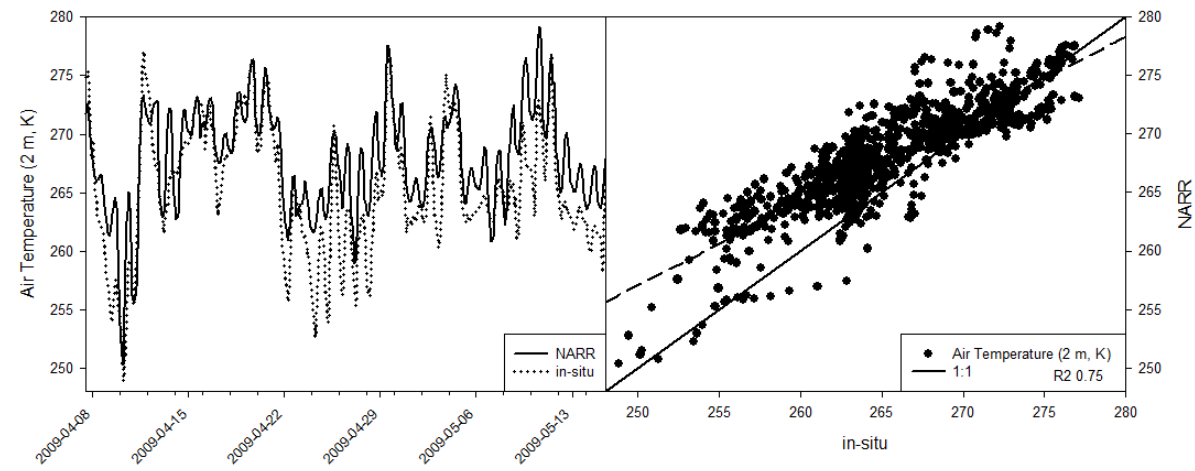

Figure 1. Air temperature $(2 \mathrm{~m}, \mathrm{~K})$ for the observation period and the relationship between NARR and in situ values.

\subsection{Multilayer snow and ice backscatter model}

The MSIB model simulates the co-polarized backscattering coefficient $(\mathrm{dB})$ for vertical and horizontal polarizations $\left(\sigma_{\mathrm{VV}}^{0}, \sigma_{\mathrm{HH}}^{0}\right)$. The model expands upon methods developed by Kim et al. (1984) and Ulaby et al. (1984). It simulates both surface (Kirchoff physical optics method for smooth surfaces per Rees, 2006) and volume scattering (based on grain number density and grain size per Drinkwater, 1989) and employs a two-way loss factor for incoming and outgoing scattering power (Winebrenner et al., 1992; Kendra et al., 1998). The model accounts for transmission, scattering, absorption, and refraction contributions from each layer volume and at layer interfaces. The permittivity $\varepsilon^{\prime}$ and dielectric loss $\varepsilon^{\prime \prime}$ for brinewetted snow are calculated using (1) the dry snow permittivity as a function of snow density (Geldsetzer et al., 2009), (2) the temperature- and frequency-dependent permittivity and dielectric loss of brine (Stogryn and Desargant, 1985), and (3) a mixture model based on the brine volume and saturation within the snow (Geldsetzer et al., 2009). The snow brine volume is a function of the snow density, temperature, and salinity and is estimated via the relative densities of brine and pure ice and the sea-ice brine volume for a given temperature and salinity (Drinkwater and Crocker, 1983; Geldsetzer et al., 2009). The model is also described in Scharien et al. (2010) and Fuller et al. (2014). Key inputs for the MSIB model are temperature, density, layer thickness, salinity, and snow grain size.

The MSIB backscatter model was run using the SNTHERM A1, A2 and B1, B2 results (see cases descriptions at the end of this paragraph), and from 3 samples of detailed in situ geophysical parameters (samples 1-3). The layered outputs from SNTHERM were amalgamated via weighted averaging into approximately $2 \mathrm{~cm}$ layers to match the vertical resolution of the in situ geophysical measurements. SNTHERM89.rev4 does not account for brine wicking in the snow and associated salinity values. This is an important consideration, as brine-wetted snow affects C-band backscatter through both increased loss and volume scattering (Barber et al., 1994; Geldsetzer et al., 2007). As such,
(1) typical salinity values (Barber et al., 1995) and (2) in situ observed salinity values (Fig. 9) were applied to SNTHERM derived snow profiles for input to the MSIB:

- SNTHERM 1: cases A1 and B1 were assigned typical salinity values for first-year sea ice and overlying snow (Barber et al., 1995).

- SNTHERM 2: cases A2 and B2 and were assigned average salinity values observed in situ (Fuller et al., 2014).

\section{Results and discussion}

\subsection{NARR and in situ meteorological comparison}

A comparison of reanalysis data to in situ measurements important to SNTHERM inputs is presented in Figs. 1-7. The NARR data correlate reasonably well for $2 \mathrm{~m}$ air temperature $\left(R^{2} 0.74\right.$, Fig. 1) and $10 \mathrm{~m}$ wind speed $\left(R^{2} 0.72\right.$, Fig. 2). The reanalysis data overestimate air temperatures below the melting point and slightly underestimate air temperatures near the melting point. Additionally, NARR data underestimate the observed diurnal temperature variation, which potentially results in overestimation or bias observed in SNTHERM simulated snow temperature (Sect. 3.2). Temperature impacts the accuracy of simulations with regard to temperature gradients through the snowpack and associated vapor fluxes. This has implications for the simulated melt and freeze cycles, potentially affecting grain growth. NARR underestimates the moderate to high wind speed, which impacts simulated aeolian snow transport mechanisms, effective precipitation particle size, density through the snowpack, and convective processes. For these reasons, effective particle size of new precipitation (input to SNTHERM) was fixed at $1 \mathrm{~mm}$, per in situ measurements of very recent snow grains that created the initial conditions used in SNTHERM B simulations. The performance of NARR is poor for relative humidity (Fig. 3), which may compound the effects of temperature inaccuracies. The relative humidity impacts energy and mass transfer 


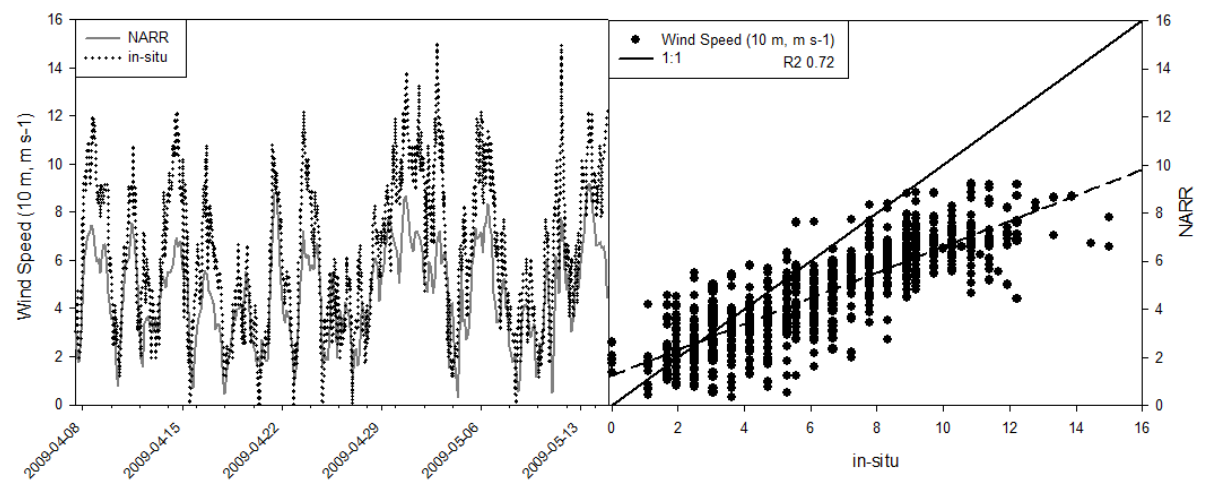

Figure 2. Wind speed $\left(10 \mathrm{~m}, \mathrm{~m} \mathrm{~s}^{-1}\right)$ for the observation period, and the relationship between NARR and in situ values.

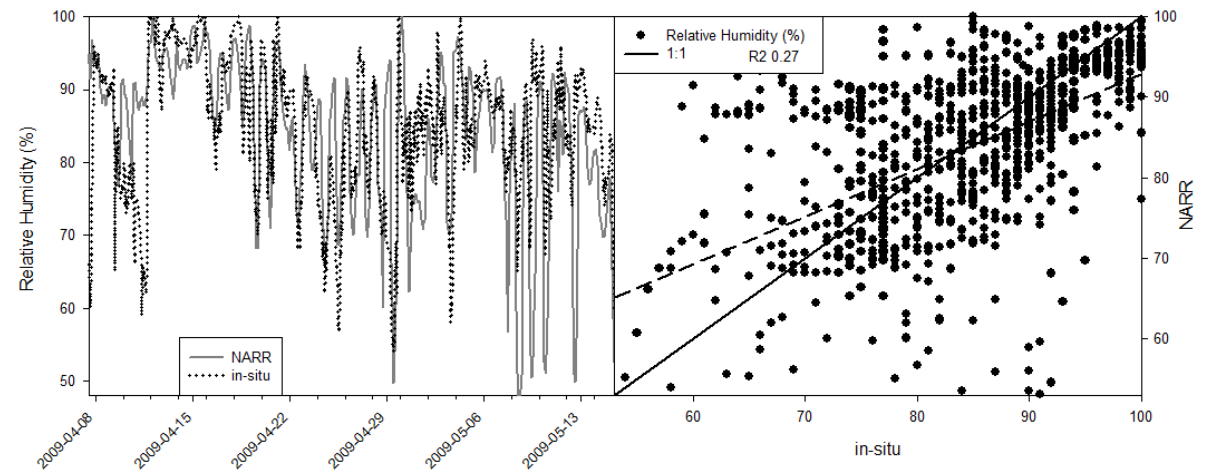

Figure 3. Relative humidity (\%) for the observation period, and the relationship between NARR and in situ values.

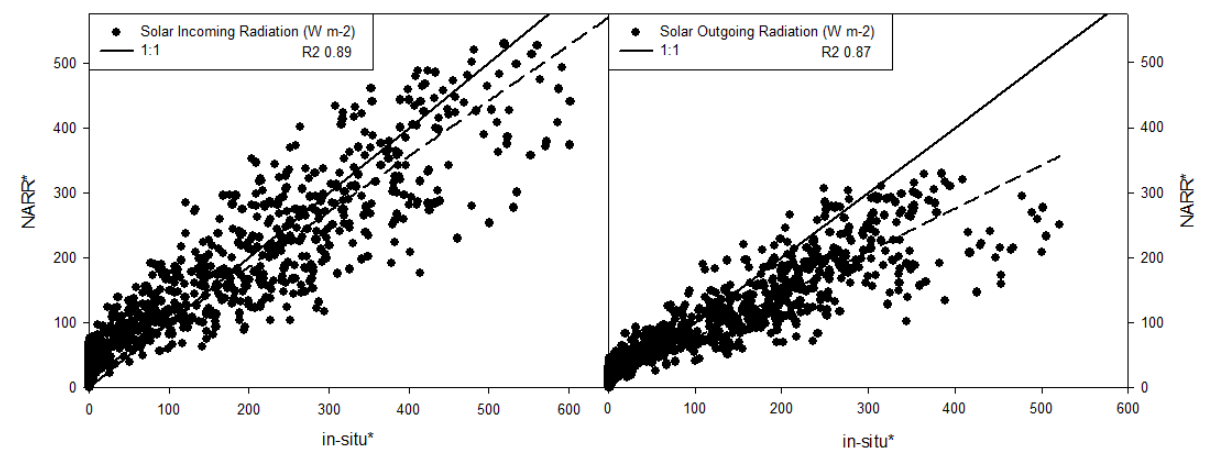

Figure 4. Incoming and outgoing shortwave radiation for the 2010 site for proxy comparison (denoted by *).

in SNTHERM through melt, sublimation, and evaporation, and vapor flux is a diver of grain growth in the model.

No in situ radiation data were acquired for the sea-ice sample location in 2009. As a proxy comparison for the effects of the mixed NARR grid on solar radiation reanalysis, shortwave radiation data acquired hourly from 13 January to 23 March 2010 are used (Fig. 4). The 2010 site was situated at an ice-covered lake within $12.25 \mathrm{~km}\left(58.719^{\circ} \mathrm{N}\right.$, $093.794^{\circ} \mathrm{W}$ ) of the 2009 sample location and located in the same NARR grid cell as the 2009 study site. The 2010 data provide a best case basis for comparison for this experiment, given the unavailability of 2009 shortwave radiation data. While not ideal, this proxy comparison lends insight and corroboration into the lower correlations of the in situ meteorological variables that we were able to more directly compare in the 2009 data set. The 2010 data are denoted with an asterisk in Figs. 4-6.

A comparison of 2010 in situ and NARR data exhibits relatively good correlations for solar radiation $\left(R^{2} 0.89\right.$ incoming, $R^{2} 0.87$ outgoing). The 2010 NARR shortwave incoming and outgoing values resulted in an albedo of approximately 0.65 , which is lower than the in situ measurements 


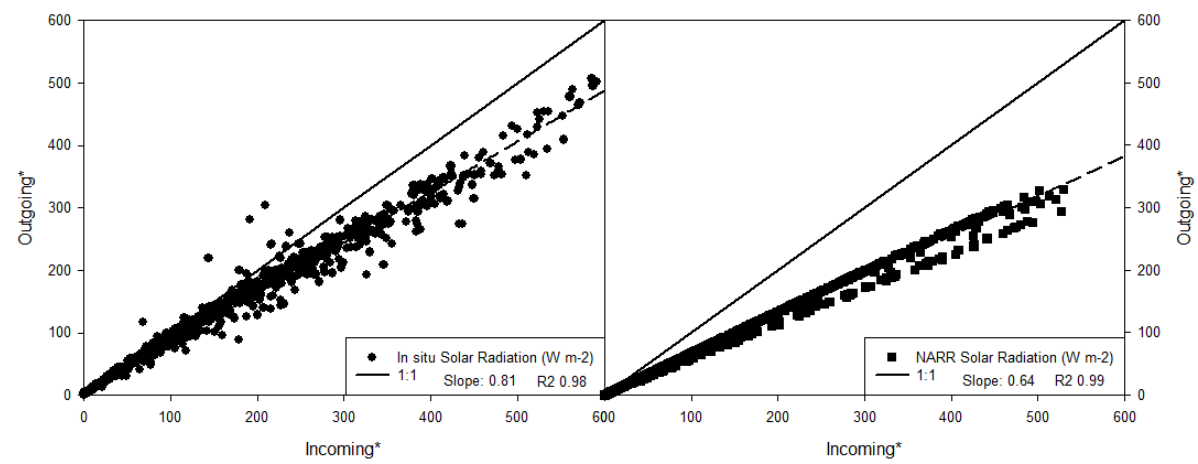

Figure 5. 2010 in situ (left) and NARR (right) incoming and outgoing shortwave radiation. NARR data from 2010 resulted in an unrepresentative albedo (slope) of 0.64 compared with 2010 in situ measurements $\left(0.81\right.$; proxy comparison denoted by $\left.{ }^{*}\right)$.

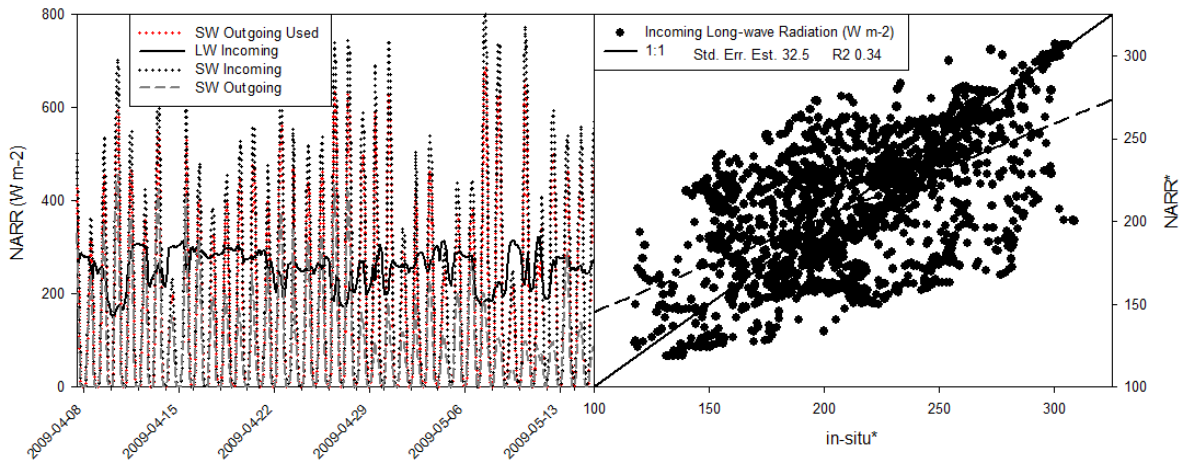

Figure 6. Left: NARR long- and shortwave radiation for the 2009 study period. Right: incoming long-wave radiation for the 2010 proxy comparison period (denoted by ${ }^{*}$ ).

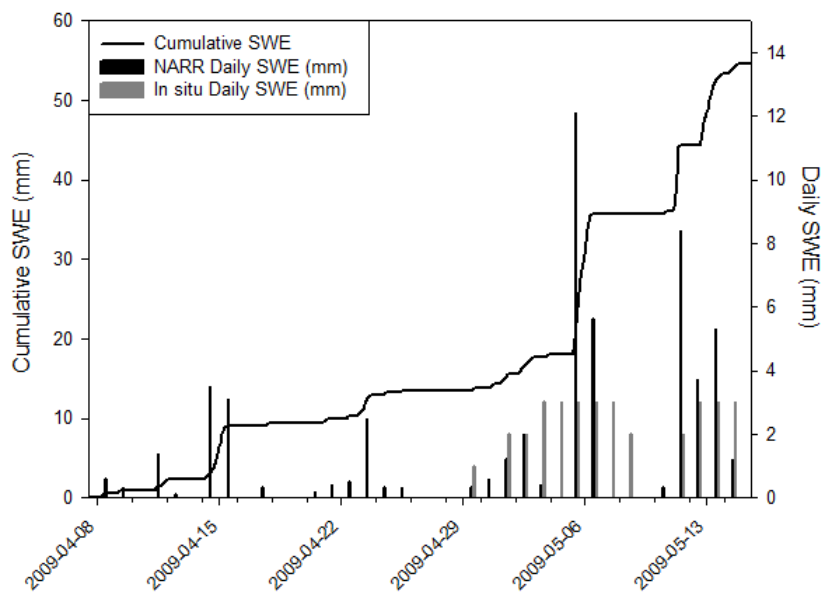

Figure 7. NARR precipitation events and SWE accumulation for the entire study period, with a comparison of in situ Nipher gauge observations for the period 30 April to 15 May.

(0.81) (Fig. 5). Initial model runs using the 2009 NARR solar radiation values entirely melted the SNTHERM-generated snowpack. As such, an albedo of 0.85 was chosen, based on the results of the 2010 data comparison and on values from literature (Curry et al., 1995; Marshall, 2011; Perovich and Polashenski, 2012).

The low correlation $\left(R^{2} 0.35\right.$, SE of the estimate 32.5$)$ for the incoming long-wave NARR radiation value (Fig. 6) impacts SNTHERM simulation accuracy of snowpack temperature (Lapo et al., 2015), as upward long-wave flux moves heat from snow and ice to atmosphere, and is dependent upon air temperature and water vapor pressure (Maykut, 1986). This may partially explain the low correlation of relative humidity, but it is not necessarily related to the NARR predicted $2 \mathrm{~m}$ air temperature, $10 \mathrm{~m}$ wind speed, or precipitation, as these are assimilated from surface observations (Mesinger et al., 2006). However, as there are no meteorological stations close to our study site, this may remain a source of error.

In situ precipitation data were acquired from Nipher snow gauge measurements for the period 30 April to 15 May 2009. These were extrapolated to daily values and show reasonable agreement for the 10-15 May precipitation event; however, the performance is poor for the previous time periods. The total SWE accumulated by NARR for the observation period is $54 \mathrm{~mm}$, with the $40 \mathrm{~mm}$ accumulation between 30 April and 15 May and compared with $35 \mathrm{~mm}$ observed SWE for the same time period. However, field notes indicate that water from the measurement was lost on 3 May 


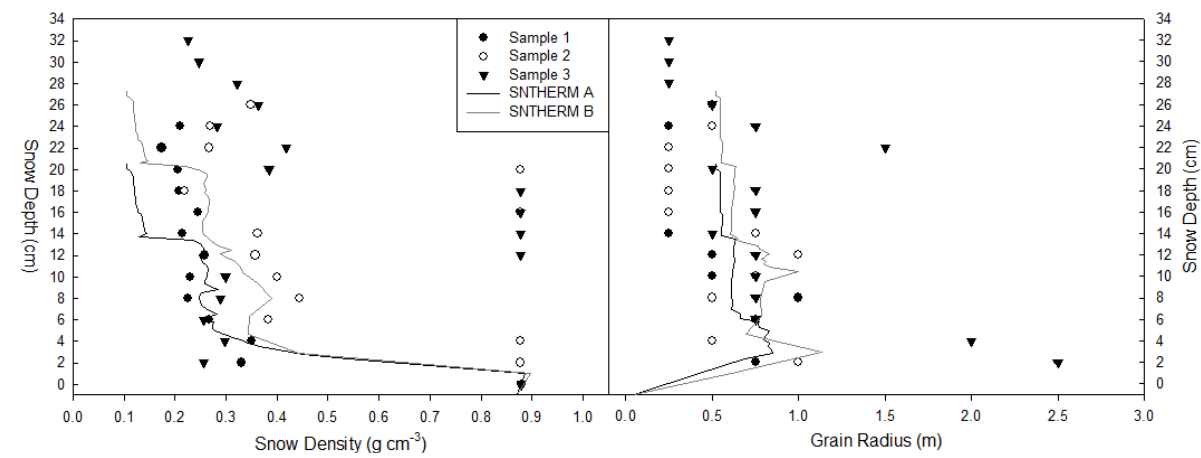

Figure 8. In situ measured and SNTHERM simulated density and grain radius values. Note the high density ice layer observed in samples 2 and 3 , between 12 and $22 \mathrm{~cm}$ snow depth.

and 10 May, partially accounting for the discrepancy. The NARR grid sampled for this work exists in a transition zone covering approximately half sea ice and half land, which likely complicates the reanalysis and may partially account for the low correlation values when compared with in situ data. The precipitation amounts derived from NARR were initially input to SNTHERM at $0.1 \mathrm{~mm}$ resolution. These very low precipitation amounts resulted in the precipitation evaporating before it could accumulate and the model reaching the nodal (layer) limit, ending the model runs prematurely. Subsequently, NARR precipitation amount was aggregated to daily values and input to 09:00 CST for each day. On days in which Environment Canada Churchill A station $\left(58.733^{\circ} \mathrm{N}, 094.050^{\circ} \mathrm{W}\right)$ and in situ field observations noted rain and snow in the same day (14, 15 April, and 11 May), the daily precipitation amount was aggregated to each precipitation type based on number of hours. This impacts liquid water inputs and drainage through the snowpack and therefore latent and sensible heat transfers in SNTHERM simulations.

\subsection{SNTHERM and in situ snow properties comparison}

The SNTHERM outputs are compared to in situ snow geophysical observations, relevant to C-band backscatter (Figs. 8-10). Three snow pits (samples 1-3) were sampled in situ and represent the various snow thicknesses and geophysical variation in the area directly adjacent to the scatterometer measurements. The snow density values show good agreement with in situ measurements, with the exception of the uppermost layers of the snowpack (Fig. 8). The density values for the lower snowpack are sensitive to initial condition (Willmes et al., 2014), as there is closer agreement between initial condition B and in situ observations. Note that the mid-pack ice layer found in samples 2 and 3 are not replicated by SNTHERM. This non-replication of ice layers by SNTHERM, which was also noted by Langlois et al. (2009), substantially affects the snowpack stratigraphy and thereby impacts thermodynamic processes controlling grain morphology, melt-water drainage, brine wicking and volume, and other melt and refreeze processes (Colbeck, 1991) of relevance to microwave scattering. The SNTHERM simulations overestimate temperature by up to $6{ }^{\circ} \mathrm{C}$ in the upper snowpack and by $2^{\circ} \mathrm{C}$ in the lower $8 \mathrm{~cm}$ of the snowpack (Fig. 8), resulting in melt layers within the simulated snowpacks. This is to be expected as NARR long-wave radiation was found to be poorly modeled with a standard error of $32.5 \mathrm{~W} \mathrm{~m}^{-2}$, causing greater-than-expected long-wave input to SNTHERM. This warmer-than-expected temperature profile increases dielectric permittivity $\left(e^{\prime}\right)$ and loss values $\left(e^{\prime \prime}\right)$ (Fig. 10) through increased liquid water content (Fig. 9). The $2{ }^{\circ} \mathrm{C}$ difference found in the bottom $8 \mathrm{~cm}$ of the snowpack is important as it impacts brine volume and allows for melting at temperatures below 0 in the MSIB model. This is compared to the relatively drier and cooler snow conditions in MSIB simulations driven by observed snow parameters for samples 1-3. The temperature difference is important as dielectric permittivity and loss, as a function of brine volume in the basal snow and near-surface sea ice, are the primary factors affecting C-band microwave backscatter signatures (Barber et al., 1994; Nghiem et al., 1995; Geldsetzer et al., 2009).

The case A and B SNTHERM initial conditions predicted snow depths of $20 \mathrm{~cm}(\mathrm{~A})$ and $27 \mathrm{~cm}$ (B), which compare reasonably well to the three in situ observations of 24,26 , and $32 \mathrm{~cm}$ (samples $1-3$, respectively). The in situ measured SWEs were 58, 96, and $143 \mathrm{~mm}$, for samples $1-3$, respectively. This compares to 43 and $67 \mathrm{~mm}$ (the latter including $22 \mathrm{~mm}$ initial condition SWE) for SNTHERM A and B, respectively. There were several rain-on-snow events during the observation period. These contributed SWE to the observed snowpack; however, SNTHERM artificially removes gravimetrically drained water from the bottom of the snowpack, removing up to $12 \mathrm{~mm}$ of SWE, when compared to NARR estimated precipitation inputs. However, melt events can be traced through the snowpack via SNTHERM outputs of snow layer conditions and temperatures. SNTHERM does take into account wind speed with regard to snow transport, density, and packing of wind slab. The discrepancy between NARR and in situ measured wind speeds may explain part 


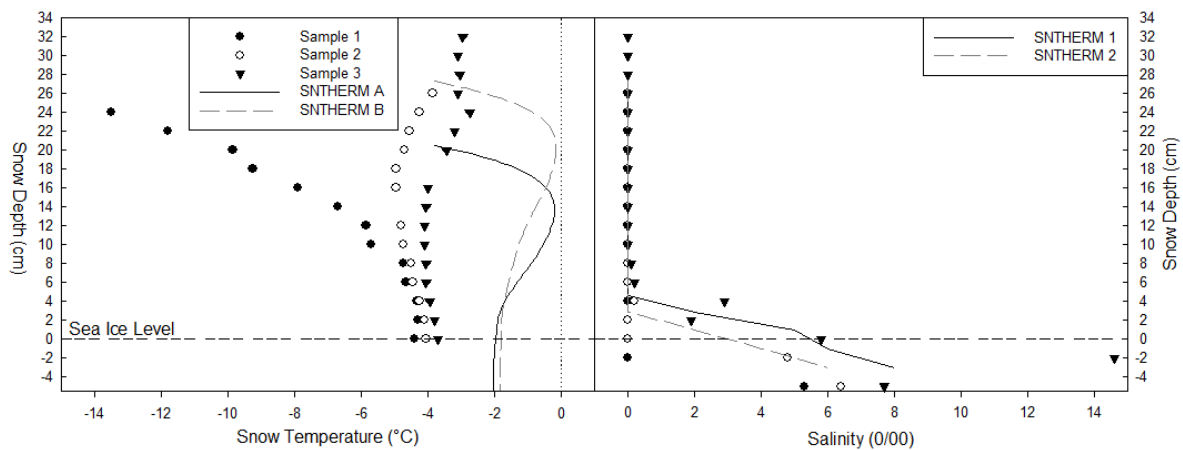

Figure 9. In situ sampled $(1,2,3)$ and SNTHERM simulated snow temperature values. In situ sampled $(1,2,3)$ salinity values, with the typical (SNTHERM 1) and lower in situ (SNTHERM 2) salinity values applied to the snow profiles input to the MSIB.

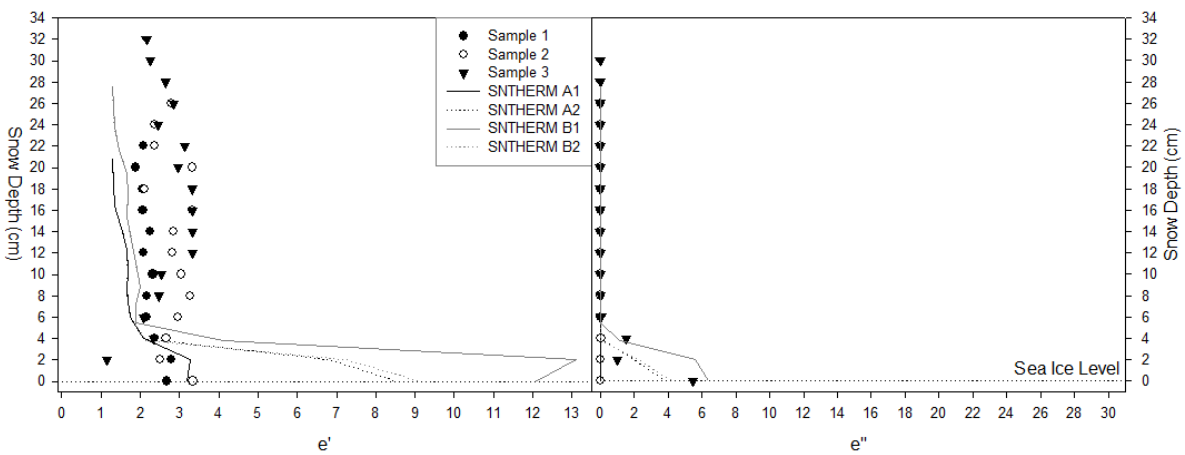

Figure 10. Modeled in situ sampled $(1,2,3)$ dielectric permittivity (left) and loss (right), with the typical (SNTHERM 1) and lower in situ (SNTHERM 2) salinity values applied to the SNTHERM snow profiles input to the MSIB.

of the SWE accumulation difference. Since SNTHERM is a one-dimensional model, advected snow supply from surrounding areas is not considered but could be a source of error, given observed wind speed was consistently between 4 and $11 \mathrm{~m} \mathrm{~s}^{-1}$, with periods of up to $15 \mathrm{~m} \mathrm{~s}^{-1}$ during this time period (Fig. 2). This may compound SWE inaccuracies when added to the artificial removal of liquid water. The higher SWE values and greater densities in the in situ observations will result in differences in thermal capacity and conductivity for a given layer, when compared to SNTHERM simulations. This, in addition to the poor long-wave input and a lack of accounting for the thermodynamic effects of brine volume throughout the SNTHERM run, contribute to the snow temperature differences (Fig. 9). Grain size agrees relatively well with observations (Fig. 8), reinforcing the choices to assign a more representative albedo to the NARR data and to fix precipitation effective particle size at $1 \mathrm{~mm}$, as grain size controls albedo and is also of primary concern to microwave backscatter.

\subsection{MSIB backscatter signature comparison}

The MSIB simulations using SNTHERM snow outputs result in backscatter values in the range of first-year sea ice (Fig. 11) (Carsey, 1992; Nghiem et al., 1995; Geldsetzer et al., 2007; Fuller et al., 2014). The relatively smaller grain sizes, lower densities, and greater dielectric permittivity and loss of SNTHERM A1 (bare ice initial condition, typical salinity profile) lead to low surface (incidence angles $\sim$ $<30^{\circ}$ ) and volume scattering (incidence angles $\sim>30^{\circ}$ ). However, when the salinity is reduced to profiled in situ averages (SNTHERM A2), surface scattering increases by $\sim 4 \mathrm{~dB}$, while volume scattering remains low with a less than $1.5 \mathrm{~dB}$ increase for incidence angles greater than $45^{\circ}$. A similar trend is observed in the SNTHERM B $(10 \mathrm{~cm}$ snow initial condition) for the two applied salinity profiles. Here the relatively larger simulated grain size and higher densities result in greater backscatter over all incidence angles for each salinity profile. Although the salinity profile is the same as measured, the temperatures in the SNTHERM snowpack are higher, which results in higher dielectric permittivity and loss for SNTHERM A and B cases when compared with in situ derived MSIB simulations (Fig. 11). The SNTHERM B2 $(10 \mathrm{~cm}$ initial snow condition, in situ salinity profile) backscatter signature is within $1 \mathrm{~dB}$ of the Sample 1 MSIB simulated backscatter for all incident angles, and for both polarization configurations. This indicates that it is possible to find agreement in backscatter signatures between NARR-driven SNTHERM snow outputs (B2) and 


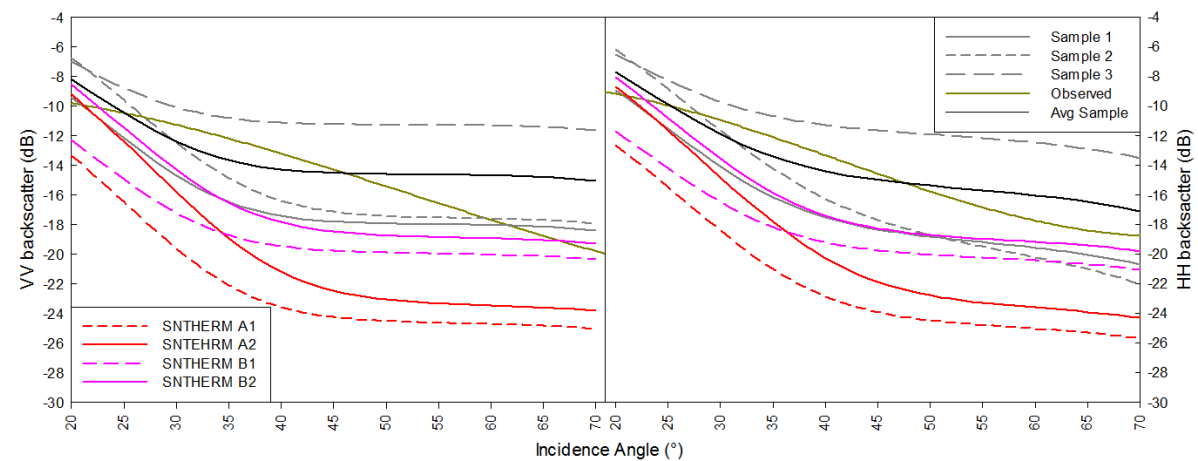

Figure 11. Comparison of simulated MSIB backscatter from samples 1, 2, and 3 and SNTHERM snow outputs A (1,2) and B(1,2). The "Avg Sample" is from samples 1 and 3, representing end members of snow condition. Observed backscatter is a cubic fit, per Fuller et al. (2014).

those simulated from in situ snow parameters (Sample 1). However, the lower correlations of NARR data relative humidity and long-wave incoming radiation result in inaccurate snow temperatures, thereby affecting dielectric properties. The inability of SNTHERM89.rev4 to simulate brine wicking in the snow cover also affects the simulated thermodynamic response and requires the application of predetermined or in situ salinity profiles.

The backscatter signatures simulated from NARR-driven SNTHERM snow outputs (A2, B2) are within $2 \mathrm{~dB}$ of observed for incidence angles less than $30^{\circ}$. This indicates that surface scattering may be simulated from SNTHERM profiles, when the in situ salinity profiles are applied. However, there is less agreement (4-6 dB difference) with regard to volume scattering, at incidence angles between 30 and $55^{\circ}$ (Fig. 11). The SNTHERM-based simulations are less reliable when compared to the relationship between the observed backscatter and the simulated backscatter for the average of samples 1 and 3. Samples 1 and 3 represented in situ snow end member conditions (Fuller et al., 2014). The averaged backscatter for samples 1 and 3 shows agreement within $2 \mathrm{~dB}$ for all incident angels for $\sigma_{\mathrm{HH}}^{0}$ observed backscatter and the same for observed $\sigma_{\mathrm{VV}}^{0}$ backscatter for incident angle less than $55^{\circ}$. The observed and simulated backscatter for samples 1-3 are in the backscatter region of first-year to multiyear sea ice. This was caused by a complexly layered snowpack with a superimposed fresh ice layer overlying the firstyear sea ice and with several rough and discontinuous low and mid-pack ice layers, which suppressed brine wicking into the snow and is fully explored in Fuller et al. (2014).

\section{Summary and conclusions}

Within the context of state-of-the-art data assimilation techniques, snow physical models may be used to drive backscatter models for comparison and optimization with satellite observations, for extrapolation to large scales with sparse in situ observation stations (Durand, 2007). North American Re- gional Reanalysis data were input to the SNTHERM snow thermodynamic model (Jordan, 1991), in order to drive the MSIB model (Scharien et al., 2010). Previous work with the MSIB model has shown that fresh ice layers superimposed over first-year sea ice are particularly relevant to C-band backscatter through the suppression of brine wicking and associated dielectric properties (Fuller et al., 2014). Therefore, a snow thermodynamic model should be able to accurately capture these key snow properties in order to drive backscatter models. The novel end-to-end assessment conducted here addresses our research questions.

\subsection{How does NARR compare to in situ meteorological data with regard to variables of importance to SNTHERM89.rev4?}

The NARR data show reasonable agreement with in situ air temperature and wind speed measurements but poor correlation to relative humidity. There is good correlation via a proxy comparison to in situ solar radiation and poor correlation with long-wave incoming radiation. A significant comparison between specific NARR and in situ precipitation amounts was not possible; however, some general agreement can be observed. The NARR incoming and outgoing solar radiation resulted in an albedo that was not representative of snow on first-year sea ice. Therefore, this was adjusted to a higher and more representative value before input to SNTHERM.

\subsection{How does SNTHERM89.rev4 output compare to in situ snow structure and geophysical properties relevant to $\mathrm{C}$-band microwave backscatter over first-year sea ice?}

SNTHERM89.rev4 reasonably captured grain size and lower snowpack density but slightly underestimated snow density for uppermost layers of the snowpack. It did not accurately capture the snow temperature; however, this was likely due to the low correlation of NARR incoming long-wave radiation and relative humidity, which affect heat flux through the 
snowpack (Lapo et al., 2015). The simulations did not capture ice lenses formed due to rain events, which contribute SWE and can influence temperature, grain morphology, and brine profiles. SNTHERM artificially removes gravimetrically drained water from the bottom of the snowpack, which removed up to $12 \mathrm{~mm}$ of SWE, when compared to NARR precipitation inputs. Additionally, the SNTHERM SWE values were low compared to in situ observations and are sensitive to initial condition (Willmes et al., 2014). The onedimensional nature of the model likely also resulted in an inability to account for snow advection via wind transport from available nearby snow accumulation zones. The publicly available SNTHERM89.rev4 accounts for sea-ice thermodynamic processes, with regard to the effects of salinity on conductivity, through layered inputs; however, it does not simulate brine wicking from sea ice to the basal snow layers, which is a key concern when considering microwave backscatter. The effective simulation of brine in the snow is important as brine suppresses both heating and cooling through brine solution and precipitation, which maintains a thermal equilibrium. Therefore, simulating the effects of brine on thermodynamic (such as temperature, albedo, longwave emission) and physical processes (such as effects of brine on basal snow grain development) is also important to accurate SNTHERM snow simulations with regard to key physical and dielectric properties controlling microwave backscatter.

\subsection{How do simulated backscatter signatures based on SNTHERM89.rev4 output compare to simulations from observed snow structure and properties and observed backscatter for complexly layered snow over first-year sea ice?}

As previously noted, to the authors' knowledge this study represents the first assessment of an end-to-end modeling suite to estimate active microwave backscatter over sea ice. The use of NARR data to drive a snow thermodynamic model, which in turn drives an active microwave backscatter model at C-band, provides a novel methodology to resolve snow and ice properties that produce ambiguity due to the one-too-many issue (Durand, 2007) in active microwave image interpretation. The backscatter signatures simulated from NARR-driven SNTHERM snow outputs (A2, B2) are within $2 \mathrm{~dB}$ of observed for incidence angles less than $30^{\circ}$, which indicates that surface scattering may be simulated from SNTHERM profiles when the in situ salinity values are applied. However, there is less agreement (4-6 dB difference) with regard to volume scattering at incidence angles between 30 and $55^{\circ}$ (Fig. 11). The SNTHERM B2 $(10 \mathrm{~cm}$ initial snow condition, in situ salinity profile) backscatter signature is with $1 \mathrm{~dB}$ of the Sample 1 (in situ geophysical measurements) MSIB simulated backscatter for all incident angles for both polarization configurations. This result holds promise for simulating snow on sea ice with re- gard to backscatter signatures. The remainder of the cases were in the backscatter range of first-year sea ice; however, backscatter intensity was lower than that of comparative in situ driven (samples 1-3) MSIB simulations. The most representative SNTHERM-driven MSIB simulation was 4$6 \mathrm{~dB}$ lower when compared to observed backscatter and when compared to the averaged in situ sample simulations (designed to account for in situ snowpack end members, and which is within $1 \mathrm{~dB}$ of observed backscatter), particularly at incidence angles greater than $30^{\circ}$. The application of in situ salinity profiles to the SNTHERM snow outputs resulted in improvements for both the bare ice and snow on sea-ice initial conditions, with regard to in situ simulated and observed backscatter comparisons.

\subsection{What are the implications of the use of the SNTHERM89.rev4 thermodynamic model in an operational approach for a radiative transfer simulation of C-band backscatter over first-year sea ice?}

This first assessment shows that although there is the possibility of achieving comparable MSIB-simulated backscatter from both SNTHERM derived and in situ snow geophysical samples for complexly layered snow on first-year sea ice, there are several constraints and considerations for improvement. (1) SNTHERM is sensitive to biases in incoming long-wave radiation (Lapo et al., 2015). Lower correlations and bias in NARR long-wave data, when compared to in situ measurements, need to be addressed by either employing in situ measurements of long-wave radiation, constraining the effects of long-wave error with snow surface temperature data (Lapo et al., 2015), or allowing SNTHERM to calculate incoming long-wave radiation based on observations of low, mid, and upper layers of cloud fraction and type. (2) The NARR outgoing solar radiation should be made to more accurately reflect conditions of snow on first-year sea ice with regard to albedo. (3) The publicly available SNTHERM89.rev4 does not simulate brine wicking into the basal snow layer, which is an important component with regard to thermodynamic response, basal layer snow dielectrics, and microwave backscatter of snow on firstyear sea ice. This also controls grain morphology and snow density, which are important to microwave backscatter interpretation. (4) The ability of SNTHERM to simulate water accumulation and refreezing at the bottom and mid-layers of the snowpack, as well as brine wicking, is necessary to accurately simulate the thermodynamic fluxes resulting in snow conditions that lead to the MSIB signatures in this study. Therefore, the current utility in using NARR data to drive SNTHERM89.rev4 may be that melt events can be traced through the snowpack via SNTHERM outputs to infer superimposed and mid-pack ice layers that may suppress brine wicking and influence thermodynamic processes. This study is important in the context of developing C-band snow in- 
version and assimilation schemes, particularly when considering expected increases in late and early season rain and melt events and associated additional complexity to snowpack stratigraphy, thermodynamics, and backscatter as a result of a warming Arctic.

Acknowledgements. We thank Melissa Peters, Peter Bezeau, JeanBenoit Madora, Alex Beaudoin, John Rogerson, Jonathan Conway, Chris Marsh, and the staff of the CNSC and PSCP. Chris Derksen is acknowledged for his advice and consultation on this paper. M. Christopher Fuller and John Yackel are funded by ArcticNet, NSERC, CSA-MDA SOAR-E, the CNSC, and the AINA. Infrastructure funding of the scatterometer is provided by the CFI. Fine Quad-Pol RADARSAT-2 data were provided via a Canadian Space Agency SOAR-E grant. Environment Canada is acknowledged for infrastructure support.

Edited by: D. Feltham

\section{References}

Andreadis, K. and Lettenmaier, D. P.: Assimilating remotely sensed snow observations into a macroscale hydrology model, Adv. Water Resour., 29, 872-886, 2006.

Barber, D. G.: Microwave remote sensing, sea ice and Arctic climate, Can. J. Phys., 61, 105-111, 2005.

Barber, D. G. and Nghiem, S. V.: The role of snow on the thermal dependence of microwave backscatter over sea ice, J. Geophys. Res., 104, 25789-25803, 1999.

Barber, D. G., Papakyriakou, T., and LeDrew, E.: On the relationship between energy fluxes, dielectric properties, and microwave scattering over snow covered first-year sea ice during the spring transition period, J. Geophys. Res., 99, 22401-22411, 1994.

Barber, D. G., Reddan, S. P., and LeDrew, E. F.: Statistical characterization of the geophysical and electrical properties of snow on landfast first-year sea ice, J. Geophys. Res., 100, 2673-2686, 1995.

Barber, D. G., Galley, R., Asplin, M. G., De Abreu, R., Warner, K.A., Pucko, M., Gupta, M., Prinsenberg, S., and Julien, S.: Perennial pack ice in the southern Beaufort Sea was not as it appeared in the summer of 2009, Geophys. Res. Lett., 36, L24501, doi:10.1029/2009GL041434, 2009.

Carsey, F. (Ed.): Microwave Remote Sensing of Sea Ice, Vol. Geophysical Monograph Series, American Geophysical Union, Washington, D.C., 1992.

Colbeck, S. C.: The layered character of snow covers, Rev. Geophys., 29, 81-96, 1991.

Crocker, G.: Observations of the snowcover on sea ice in the Gulf of Bothnia, Int. J. Remote Sens., 13, 2433-2445, 1992.

Curry, J. A., Schramm, J. L., and Ebert, E. E.: Sea ice-albedo climate feedback mechanism, J. Climate, 8, 240-247, 1995.

Drinkwater, M. R.: LIMEX' 87 ice surface characteristics: implications for C-band SAR backscatter signatures, IEEE T. Geosci. Remote, 27, 501-513, 1989.

Drinkwater, M., Crocker, G.: Modeling changes in the dielectric and scattering properties of young snow covered sea ice at $\mathrm{GHz}$ frequencies. J. Glaciol., 34, 274-282, 1988.
Durand, M.: Feasibility of snowpack characterization using a multifrequency data assimilation scheme, Doctor of Philosophy Thesis. UMI Microform, Proquest LLC, Los Angeles, CA, 2007.

Essery, R., Morin, S., Lejeune, Y., and Menard, C.: A comparison of 1701 snow models using observations from an alpine site, Adv. Water Resour., 55, 131-148, 2013.

Fuller, M., Geldsetzer, T., Gill, J., Yackel, J., and Derksen, C.: Cband backscatter from a complexly-layered snow cover on firstyear sea ice, Hydrol. Process., 28, 4641-4625, 2014.

Geldsetzer, T., Mead, J. B., Yackel, J. J., Scharien, R. S., and Howell, S. E.: Surface-based polarimetric C-band scatterometer for field measurement of sea ice, IEEE T. Geosci. Remote, 45, 34053416, 2007.

Geldsetzer, T., Langlois, A., and Yackel, J.: Dielectric properties of brine-wetted snow on first-year sea ice, Cold Re.g. Sci. Technol., 58, 47-56, 2009.

Gill, J. and Yackel, J.: Evaluation of C-band SAR polarimetric parameters for discrimination of first-year sea ice types, Can. J. Remote Sens., 38, 306-323, 2012.

Gill, J., Yackel, J., and Geldsetzer, T.: Analysis of consistency in first-year sea ice classification potential of C-band SAR polarimetric parameters, Can. J. Remote Sens., 39, 101-117, 2014.

Jordan, R.: A one-dimensional temperature model for a snow cover: technical documentation for SNTHERM 89, US Army Corps of Engineers, Hanover, NH, USA, 1991.

Jordan, R. and Andreas, E.: Heat budget of snow-covered sea ice at North Pole 4, J. Geophys. Res., 104, 7785-7806, 1999.

Kendra, J. R., Sarabandi, K., and Ulaby, F. T.: Radar measurements of snow: experiments and analysis, IEEE T. Geosci. Remote, 36, 864-879, 1998.

Kim, Y. S., Onsott, R. G., and Moore, R. K.: The effect of a snow cover on microwave backscatter from sea ice, IEEE J. Ocean. Engin., 9, 383-388, 1984.

Kohn, J. and Royer, A.: AMSER-E data inversion for soil temperature estimation under snow cover, Remote Sens. Environ., 114, 2951-2961, 2010.

Langlois, A., Barber, D. G., and Hwang, B. J.: Development of a winter snow water equivalent algorithm using in situ passive microwave radiometry over snow covered first-year sea ice, Remote Sens. Environ., 106, 75-88, 2007.

Langlois, A., Brucker, L., Kohn, J., Royer, A., Derksen, C., Cliche, P., Picard, G., Willamet, J., and Fily, M.: Simulation for snow water equivalent (SWE) using thermodynamic snow models in Quebec, Canada, J. Hydrometeorol., 1447-1463, 2009.

Langlois, A., Royer, A., Derksen, C.,Montpetit, B., Dupont, F., Goita, K.: Coupling of the snow thermodynamic model SNOWPACK with the microwave emission model of layered snowpacks for subarctic and arctic snow water equivalent retrievals, Water Resour. Res., 48, 1-14, 2012.

Lapo, K., Hinkelman, L., Raleigh, M., and Lundquist, J.: Impact of errors in the downwelling irradiances on simulations of snow water equivalent, snow surface temperature, and the snow energy balance, Water Resour. Res., 51, 1-22, doi:10.1002/2014WR016259, 2015.

Marshall, S.: The Cryosphere, Princeton University Press, New Jersey, NY, 2011.

Matcalfe, J. and Goodison, B.: Correction of Canadian winter precipitation data, Eighth symposium on meteorological observa- 
tions and instrumentations, American Meteorological Society, Anaheim, CA, 338-343, 1993.

Maykut, G.: The surface heat and mass balance, in: The Geophysics of Sea Ice, Vol. Series B: Physics Volume 146, edited by: Untersteiner, N., Plenum Press, New York, NY, 395-464, 1986.

Maykut, G. A.: Large-scale heat exchange and ice production in the Central Arctic, J. Geophys. Res., 87, 7971-7984, 1982.

Mesinger, F., DiMego, G., Kalnay, E., Mitchel, K., Shafran, P., Ebisuzaki, Jovic, D., Wollen, J., Rogers, E., Berbery, E., Ek, M., Fan, Y., Grumbine, R., Higgins, W., Li, H., Lin, Y., Mankin, G., Parrish, D., and Shi, W.: North American regional reanalysis, B. Am. Meteorol. Soc., 87, 343-360, 2006.

Monpetit, B., Royer, A., Roy, A., Langlois, A., and Derksen, C.: Snow microwave emission modeling of ice lenses within a snowpack using the Microwave Emission Model for Layered Snowpacks, IEEE T. Geosci. Remote, 51, 4705-4717, 2013.

Nghiem, S., Kwok, R., Yueh, S., and Drinkwater, M.: Polarimetric signatures of sea ice 2. Experimental observations, J. Geophys. Res., 100, 13681-13698, 1995.

Perovich, D. and Polashenski, C.: Albedo evolution of seasonal Arctic sea ice, Geophys. Res. Lett., 39, L08501, doi:10.1029/2012GL051432, 2012.

Proksch, M., Mätzler, C., Wiesmann, A., Lemmetyinen, J., Schwank, M., Löwe, H., and Schneebeli, M.: MEMLS3\&a: Microwave Emission Model of Layered Snowpacks adapted to include backscattering, Geosci. Model Dev., 8, 2611-2626, doi:10.5194/gmd-8-2611-2015, 2015.

Pulliainen, J.: Mapping of snow water equivalent and snow depth in boreal and sub-arctic zones by assimilating space-borne microwave radiometer data and ground-based observations, Remote Sens. Environ., 101, 257-269, 2006.

Rees, W. G.: Remote Sensing of Snow and Ice, Taylor and Francis Group, Cambridge, 2006.

Reichle, R.: Data assimilation methods in the Earth sciences, Adv. Water Resour., 31, 1411-1418, 2008.

Robok, A.: Ice and snow feedbacks and the latitudinal and seasonal distribution of climate sensitivity, J. Atmos. Sci., 40, 986-997, 1983.

Roy, A., Royer, A., Wigneron, J.-P., Langlois, A., Bergeron, J., and Cliche, P.: A simple parameterization for a Boreal forest radiative transfer model at microwave frequencies, Remote Sens. Environ., 124, 371-383, 2012.

Scharien, R. K., Geldsetzer, T., Barber, D. G., Yackel, J. J., and Langlois, A.: Physical, dielectric, and $\mathrm{C}$ band microwave scattering properties of first-year sea ice during advanced melt, J. Geophys. Res., 115, C12026, doi:10.1029/2010JC006257, 2010.

Schwerdtfeger, P.: The thermal properties of sea ice, J. Glaciol., 4, 789-807, 1963.

Serreze, M. and Barry, R.: The Arctic Climate System, Cambridge University Press, Cambridge, UK, 2005.
SNTHERM - S. B. University of California, Producer: From Institute for Computational Earth System Science, available at: http: //www.icess.ucsb.edu/ mtc/sntherm_docs/sntherm.html, last access: 15 March 2015.

Stogryn, A. and Desargent, G.: The dielectric properties of brine in sea ice at microwave frequencies, IEEE Trans. Antenn. Propag., 33, 523-532, 1985.

Sturm, M. and Massom, R.: Snow and sea ice, in: Sea Ice, edited by: Thomas, D. N. and Dieckmann, G., 2nd Edn., Wiley-Blackwell, 153-204, 2009.

Sun, C., Walker, J., and Houser, P.: A simple snow-atmosphere-soil transfer model, J. Geophys. Res., 104, 19587-19594, 2004.

Trenberth, K. E., Jones, P. D., Ambenje, P., Bojariu, R., Easterling, D., Klein, A., Tank, D., Parker, D., Renwick, J., Rahimzadeh, F., Rusticucci, M., Soden, B., and Zhai, P.: Observations: surface and atmospheric climate change, in: Climate Change 2007: The Physical Science Basis, edited by: Solomon, S., Qin, D., Manning, M., Chen, Z., Marquis, M., Averyt, K., Tignor, M., and Miller, H., Contribution of Working Group I to the Fourth Assessment Report of the Intergovernmental Panel on Climate Change, Cambridge University Press, Cambridge, UK and New York, NY, USA, 235-336, 2007.

Trodahl, H. J., Wilkinson, S. O. F., McGuinness, M. J., and Haskell, T. G.: Thermal conductivity of sea ice; dependence on temperature and depth, Geophys. Res. Lett., 28, 1279-1282, 2001.

Ulaby, F. T., Stiles, H. W., and Abdelrazik, M.: Snowcover influence on backscattering from terrain, IEEE T. Geosci. Remote, 22, 126-133, 1984.

Wadhams, P.: Ice in the Ocean, Gordon and Breach Science Publishers, Amsterdam, the Netherlands, 2000.

Warner, K., Iacozza, J., Scharien, R., and Barber, D.: On the classification of melt season first-year and multi-year sea ice in the Beaufort Sea using Radarsat-2 data, Int. J. Remote Sens., 34, 3760-3744, 2013.

Wiesmann, A., Fierz, C., and Matzler, C.: Simulation of microwave emission from physically modeled snowpacks, Ann. Glaciol., 31, 397-405, 2000.

Willmes, S., Nicolaus, M., and Haas, C.: The microwave emissivity variability of snow covered first-year sea ice from late winter to early summer: a model study, The Cryosphere, 8, 891-904, doi:10.5194/tc-8-891-2014, 2014.

Winebrenner, D., Bredow, J., Fung, A., Drinkwater, M., Nghiem, S., Gow, A., Perovich, D., Grenfell, T., Han, H., Kong, J., Lee, J., Mudaliar, S., Onstott, R., Tsang, L., and West, R.: Microwave sea ice signature modeling, in: Microwave Remote Sensing of Sea Ice, edited by: Carsey, F., Vol. Geophysical Monograph Series, AGU, Washington, D. C., 137-171, 1992.

Yackel, J. J. and Barber, D. G.: Observations of snow water equivalent change on landfast first-year sea ice using synthetic aperture radar data, IEEE T. Geosci. Remote, 45, 1005-1015, 2007. 